\title{
ARTIGOORIGINAL
}

\section{Uma revisão das técnicas computacionais para contagem de ovos de Aedes aegypti em imagens de ovitrampas}

\section{A review of computational techniques for counting Aedes aegypti eggs in ovitrap images}

\author{
André Luiz Brun ${ }^{\oplus, 1}$, Pedro Lucas Moraes ${ }^{1}$, Claudia Brandelero Rizzi ${ }^{\oplus}, 1$, \\ Rogério Luis Rizzi ${ }^{\oplus, 1}$ \\ ${ }^{1}$ Universidade Estadual do Oeste do Paraná - UNIOESTE \\ andre.brun@unioeste.br,plmoraes12@hotmail.com,claudia.rizzi@unioeste.br,rogerio.rizzi@unioeste.br
}

Recebido: 30/04/2020. Revisado: 13/07/2020. Aceito: 14/10/2020.

\begin{abstract}
Resumo
A dengue é uma doença viral infecciosa, transmitida pelo mosquito Aedes (albopictus e aegypti), que está presente em mais de 100 países. Apesar do número frequente e crescente de casos confirmados, não existe vacina eficaz contra a dengue. A estratégia mais eficiente é o acompanhamento e controle do vetor, realizado principalmente com a limpeza de recipientes que são possíveis criadouros. Uma das alternativas para o monitoramento é a estimação da quantidade de mosquitos por região. Isso pode ser feito através da contagem de ovos em imagens de ovitrampas, que são armadilhas compostas por um recipiente parcialmente ocupado por água ou alguma infusão no qual é inserida uma palheta ou lâmina, proporcionando um ambiente adequado para oviposição. A palheta é fotografada e a contagem dos ovos é feita manualmente. As imagens contêm uma quantidade variável de ovos podendo alcançar milhares de unidades, tornando o trabalho de contagem dispendioso e passivo a erros devido ao cansaço humano. Uma alternativa para auxiliar na estimação do número de ovos presentes nas ovitrampas são os métodos de contagem automática. $\mathrm{O}$ atual trabalho apresenta um levantamento bibliográfico de trabalhos de contagem automática de ovos presentes na literatura, visando identificar as diferentes técnicas usadas na solução do problema, bem como os fatores de maior influência no processo e possíveis desafios que ainda demandam soluções.
\end{abstract}

Palavras-Chave: Processamento de imagens; Contagem de ovos; Ovitrampas.

\section{Abstract}

Dengue is an infectious viral disease, transmitted by the Aedes mosquito (albopictus and aegypti), which is present in more than 100 countries. Despite the frequent and growing number of confirmed cases, there is no effective vaccine against dengue. The most efficient strategy is monitoring and controlling the vector, performed mainly by cleaning containers that are possible breeding sites. One of the alternatives for monitoring is the estimation of the number of mosquitoes per region. This can be done by counting eggs in images of ovitraps, which are traps composed of a container partially occupied by water or some infusion in which a pallet or blade is inserted, providing a suitable environment for oviposition. The pallet is photographed and the eggs are counted manually. The images contain a variable amount of eggs that can reach thousands of units, making counting work expensive and passive to errors due to human fatigue. An alternative to assist in estimating the number of eggs present in ovitraps are automatic counting methods. The current work presents a bibliographic survey of automatic egg counting works present in the literature, identifying how different techniques are used in solving problems, as well as the factors of greatest influence in the process and possible challenges that still demand solutions. 


\section{Introdução}

A dengue é uma doença febril aguda presente em mais de cem países e é causada por um arbovírus do gênero Flavivírus. Diversas espécies de mosquitos Aedes podem servir de vetor para a doença. No Brasil, duas delas se fazem presentes: o Aedes albopictus e, principalmente, o Aedes aegypti, um mosquito considerado muito ativo, de hábitos diurnos e urbano. A transmissão da doença se dá quando a fêmea da espécie, que se alimenta de sangue, se contamina ao picar um indivíduo durante a fase de viremia. Esta fêmea, após um prazo de 10 a 14 dias, quando passa ao estado infectivo, será capaz de transmitir o vírus a todas as pessoas que picar (Rizzi et al., 2016).

Segundo a Organização Mundial de Saúde (OMS), mais de 50 milhões de pessoas são contaminadas todos os anos, das quais 500 são diagnosticadas como dengue hemorrágica. A entidade aponta que cerca de $20 \mathrm{mil}$ pessoas morrem anualmente em decorrência da doença. Segundo Mukherji and Kaushik (2015), cerca de 70\% dos casos da doença ocorrem na Ásia, principalmente na Índia. Ainda segundo a OMS, acredita-se que aproximadamente 2,5 bilhões de pessoas estejam em risco de contrair a doença.

Em boletim epidemiológico apresentado pelo Ministério da Saúde, verificou-se que no primeiro semestre de 2020 (até o dia 18/07) foram notificados 905.912 casos prováveis de dengue no Brasil, o que representa uma taxa de incidência de 431,10 casos por 100 mil habitantes. Dos casos positivos 707 foram classificados como dengue grave e 8.288 como dengue com sinais de alarme. Ao todo foram confirmados 433 óbitos, no período, em decorrência da dengue (Brasil, 2020).

Embora exista vacina contra a dengue, a exemplo da Dengvaxia, do laboratório Sanofi-Aventis, aprovada no Brasil em 2015, ela precisa ser aperfeiçoada por diversos motivos, incluindo o fato de que não é recomendada para indivíduos soronegativos. Além dos casos assintomáticos, como nem todos os indivíduos sabem efetivamente se contraíram ou não dengue, trata-se de um problema sério no que tange à vacinação em massa (Brasil, 2017). Neste sentido ainda são mais recomendadas ações objetivando o controle do vetor.

Estes procedimentos tentam diminuir a população do mosquito atacando as diversas fases em que ele se apresenta. Políticas são fundamentais. Exemplos são o estímulo à limpeza constante em receptáculos que podem se tornar criadouros do mosquito, aplicação pontual de inseticida onde há larvas e pupas e, apenas em última instância nos casos de epidemias, pulverização em aéreas específicas para o combate do Aedes na fase alada.

Segundo Brady et al. (2015), o Brasil é o país com o sistema de vigilância mais abrangente, envolvendo grande parte da população nacional e cobrindo mais de 5.570 municípios, mantendo dados registrados mensalmente ao longo de dez ou mais anos. O país já dedica recursos significativos para o controle de vetores, incluindo os transmissores da dengue, além de ter uma comunidade de pesquisadores dedicada a estudar o avanço de epidemias, suas causas e consequências.
Segundo Garcia et al. (2019), uma das formas mais eficientes para estimação, detecção e monitoramento da presença do vetor é através da contagem de ovos presentes em uma determinada localização. A ideia é que, com base nestes valores, pode-se estimar o número de vetores que chegarão às fases seguintes (larva, pupa e alada ou adulta).

Uma das maneiras para coletar ovos de mosquito é por meio da utilização de ovitrampas, que são armadilhas formadas por um recipiente plástico, geralmente preto fosco. O invólucro é parcialmente preenchido por água ou por algum tipo de infusão que tem a função de atrair a fêmea para a oviposição, e uma lâmina (ou placa) com superfície rugosa posicionada de forma que fique parcialmente submersa (Silva and Limongi, 2018). A placa normalmente é composta de compensado de madeira, algodão ou papel filtro.

Em geral, uma ovitrampa tem cerca de $12 \mathrm{~cm}$ de profundidade com uma abertura circular com $5 \mathrm{~cm}$ de raio. Os pesquisadores sugerem ainda a adoção de cerca de $200 \mathrm{ml}$ de líquido por armadilha (Brasil et al., 2015).

As ovitrampas são dispositivos, econômicos e que não incorrem em danos ao meio ambiente desde que devidamente acompanhadas. Elas são indicadas para regiões com mão de obra disponível, uma vez que deverão ser vistoriadas e substituídas, impreterivelmente no período que antecede à eclosão dos ovos, sob pena de contribuir para sua proliferação. Porém, quando bem monitoradas, segundo Brasil et al. (2015), elas viabilizam identificar com antecedência possíveis infestações.

O mosquito fêmea vê na armadilha o cenário propício para a oviposição, uma vez que os ovos ficarão aderidos à lâmina próximos da superfície da água e, quando o nível desta atingir os ovos eles eclodirão e as larvas terão acesso à água presente na estrutura.

As ovitrampas são posicionadas em locais em que há vetores e, depois de um intervalo de tempo (geralmente 7 dias), as lâminas são substituídas e o processo de contagem é realizado, normalmente de forma manual. A Fig. 1 apresenta o segmento de imagem de uma lâmina contendo ovos de Aedes aegypti. Na ilustração é possível perceber a existência de diversos elementos alongados com coloração mais escura. Estes são os ovos depositados pela fêmea do mosquito.

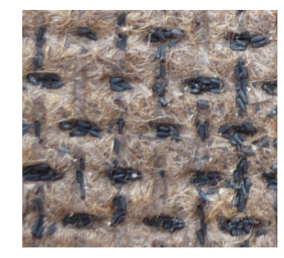

Figura 1: Lâmina de ovitrampa contendo ovos de Aedes. Fonte: Portela (2009)

O responsável faz uso de algum mecanismo de microscopia para auxiliar na visualização das placas. Então, um a um os ovos são contados.

O processo quando realizado desta forma é bastante cansativo e sujeito a falhas, uma vez que demanda 
muito esforço visual contínuo do responsável. Além disso, como citado por Brasil et al. (2015), pode haver ainda variações nas leituras, quando feitas por diferentes profissionais ou quando há sobreposição de ovos.

Segundo Tiba et al. (2011), placas com 100 ovos podem ser contadas manualmente por uma pessoa em um ou dois minutos. No entanto, placas mais densas, com cerca de 2000 ovos demandam em torno de 30 minutos para serem contabilizadas. Ao longo do dia a pessoa que efetua as contagens pode cometer erros devido à fadiga do processo. Segundo os autores outro problema no processo de contagem manual é que a lente do microscópio não cobre toda a área da palheta sendo necessário deslocamento. Isso pode fazer com que regiões sejam contadas duas vezes ou que áreas não sejam contabilizadas. Além disso, há a demanda e o custo do profissional responsável pela tarefa.

Uma estratégia encontrada para tornar o processo de contagem dos ovos do Aedes menos oneroso e possivelmente mais preciso é utilizar uma abordagem computacional. Isto porque o computador não sucumbe à exaustão e, como possui comportamento determinístico, pode ser empregado de forma contínua na contagem.

Entretanto, para que o algoritmo de contabilização tenha sucesso, a captura das imagens das placas deve ser a melhor possível evitando tendenciosidades de origem. Além disso, os parâmetros de identificação e contagem automática devem ser adequados para cada caso em específico visto que de acordo com as características do processo de aquisição (resolução, distância, iluminação) o desempenho do método pode variar.

Assim, o grande desafio no escopo computacional é tentar empregar estratégias de processamento de imagens para tentar otimizar as características presentes na ilustração, bem como critérios para a identificação precisa e individual dos ovos presentes na imagem.

Abordagens mais recentes têm sido propostas no sentido de adotar técnicas inteligentes para realizar a contagem. Tais estratégias fazem parte da área de Aprendizagem de Máquina, que objetiva dotar o computador com a capacidade de aprender com base em experiências prévias de forma que seja capaz de reconhecer novos cenários a partir do que aprendeu (Kumar et al., 2009).

Neste trabalho buscou-se sistematizar um levantamento bibliográfico acerca das abordagens de contagem automática do número de ovos presentes em palhetas de ovitrampas a partir da suas imagens digitais.

Fez-se o levantamento bibliográfico onde foram acessados os mais importantes repositórios de publicações científicas (IEEExplore, Intech Open, ResearchGate, ScienceDirect, Portal de Periódicos Capes, Web of Science, ACM, Springer Link, Scopus, SciFinder e Scielo) em busca de artigos que contemplassem o tema, adotando-se diferentes conjuntos de palavras-chave em português e em inglês, sendo elas: dengue, contagem, ovos, imagens, ovitrampas, (counting, eggs, images e ovitraps), modificando-se o conjunto de palavraschave a cada pesquisa afim de abranger o maior número possível de artigos relacionados. Para seleção dos artigos, leu-se o abstract de cada trabalho analisando se ele contemplava o tema proposto.

Em um segundo momento fez-se a busca pelos trabalhos citados nos artigos compilados na primeira rodada. Esse processo foi então repetido novamente, visando obter o maior número de trabalhos possível. Por fim realizou-se a adoção de ferramentas de buscas online para identificar novos trabalhos que ainda não estivessem presentes no conjunto levantado.

O restante do trabalho é apresentado da seguinte forma: Na Seção 2 são caracterizadas soluções computacionais para contagem automática de ovos de Aedes disponíveis na literatura. Na seção seguinte são feitas observações gerais sobre os métodos de contagem e na Seção 4 são apresentadas as principais considerações finais decorrentes desta pesquisa.

\section{Técnicas computacionais de contagem}

O método de contagem proposto por Mains et al. (2008) não focou em ovitrampas com as mesmas características daquelas apresentadas na Seção 1. Durante os experimentos foram adotadas armadilhas constituídas de um copo em que um papel foi aderido à parede interna do mesmo. Além disso, a avaliação dos métodos deu-se sobre conjuntos de ovos do Aedes aegypti, albopictus e polynesiensis.

O papel preso no interior das armadilhas foi então retirado e escaneado para contagem manual, de forma a construir um padrão ouro para cada imagem. O padrão ouro ou ground truth consiste no resultado real ou esperado de um determinado método. No nosso contexto, o padrão representa o número real de ovos observados nas palhetas de ovitrampas. Assim, quanto mais próxima do padrão outro for a contagem realizada pelo método, melhor ele é considerado.

As imagens em formato true color e com resolução de 600 dpi são submetidas à quantização para 256 tons de cinza que é seguida por uma limiarização de patamar único, eliminando os pixels mais claros que correspondem ao fundo da imagem.

Depois de binarizada a imagem, possibilita-se ao usuário escolher conjuntos de pixels pretos que ele sabe se tratar de ruídos e eliminá-los. Além disso, o software faz a análise da dimensão dos grupos. Aqueles com área inferior a 30 pixels quadrados são descartados, bem como aqueles que estão nas bordas da imagem. Os resultados mostraram que a contagem efetuada através da técnica proposta alcançaram resultados muito similares aqueles obtidos de forma manual. A análise de resíduo mostrou não haver diferença significativa entre o padrão ouro e os valores estimados pelo método computacional. A precisão da contagem foi constatada tanto para o Aedes aegypti quanto para o albopictus e polynesiensis.

Três abordagens para contagem automática de ovos de Aedes aegypti são apresentadas no trabalho de Santos et al. (2008). Nas três soluções apresentadas faz-se, inicialmente, a conversão das imagens em formato RGB (Red, Green e Blue) para o formato $\mathrm{YIQ}^{1}$ (Luminância,

${ }_{1}^{1}$ O YIQ é o espaço de cores usado pelo sistema de TV em cores 
Interpolação e Quadratura). As imagens originais das ovitrampas têm dimensão 3000 x 2300 pixels com uma resolução de 700 dpi. No entanto, no trabalho são usadas sub-imagens, as quais não tem seu tamanho especificado.

A primeira estratégia adota então uma abordagem de limiarização (na banda I) com limiar fixo em 130, definido pelos projetistas com base em testes prévios. Depois de limiarizada a imagem é submetida à análise de componentes conectados, onde são identificados os conjuntos de pixels que têm vizinhos de mesma cor, neste caso, representando os ovos. Aqueles conjuntos compostos por menos de 100 pixels são descartados por não constituir região suficiente para corresponder a um ovo. Em seguida aplica-se uma operação morfológica de fechamento, com um elemento estruturante elíptico de dimensões $8 \times 13$ pixels. Na etapa de contagem então dividiu-se o tamanho dos conjuntos conectados pelo tamanho médio dos ovos (170 pixels), obtendo-se assim uma estimação do número de ovos presentes naquele grupo.

A segunda estratégia proposta adota apenas uma limiarização (na banda I) com limiar fixo em 200. A terceira abordagem emprega o método de $\mathrm{K}$-means para binarizar a imagem. Nesta solução foram adotadas 4 classes, uma taxa de aprendizagem de 0,1 e um total de 200 iterações. Nas duas abordagens o processo de contagem divide o tamanho dos conjuntos de pixels brancos pelo tamanho médio do ovo que neste caso foi de 220 pixels.

A validação dos métodos propostos foi realizada em um conjunto composto de 6 imagens. Para critérios de avaliação, cada imagem foi submetida à contagem manual dos ovos de forma a se conhecer o padrão ouro de cada uma. Segundo os autores, a primeira estratégia teve um erro médio de $9 \%$ enquanto a segunda alcançou uma taxa média de acerto de aproximadamente 92,67\%. Já a terceira abordagem apresentou um erro médio em torno de $7,88 \%$.

O trabalho de Mello et al. (2008) tem grande sobreposição com aquele apresentado por Santos et al. (2008). No trabalho de Mello e demais pesquisadores são apresentados 3 métodos para contagem de ovos de Aedes, dois dos quais já foram apresentados por Santos et al. (2008) e mencionados nos parágrafos anteriores. As imagens colhidas para os experimentos têm dimensão de 3072 x 2304 pixels e empregam resolução de 700 dpi. Porém, estas foram divididas em sub-imagens para os experimentos. Não é descrito como foram obtidas tais sub-imagens assim como suas dimensões.

O primeiro método proposto transforma as imagens originais em formato RGB para o formato $\mathrm{HSV}^{2}$ (Matiz, Saturação e Valor, do inglês, Hue, Saturation e Value). Avaliando-se os três canais os autores optaram por adotar o canal $\mathrm{H}$ uma vez que foi aquele que indicou maior dicotomia entre fundo e objeto de interesse. Para

NTSC, adotado principalmente nas Américas do Norte e Central e no Japão

${ }^{2}$ O sistema HSV foi proposto por Alvy Ray Smith em 1974 visando uma concepção intuitiva da técnica utilizada por artistas ao misturar cores básicas para obtenção de cores compostas a etapa de binarização foi adotado a limiarização adaptativa proposto por Huang and Wang (1995).

Depois de binarizada é realizada a análise dos componentes conectados. Aqueles cujo tamanho for inferior a 100 pixels são eliminados, uma vez que não correspondem a ovos. Em seguida aplica-se uma operação de fechamento, com elemento estruturante elíptico (similar aos ovos) com medidas $18 \times 30$ pixels. A contagem é feita então dividindo-se o tamanho dos componentes conectados por 170 pixels (tamanho médio estimado para o cada ovo).

O segundo e terceiro métodos são os mesmos descritos no trabalho de Santos et al. (2008) para a segunda (limiar fixo em 200) e terceira (K-means) estratégias.

O processo de validação deu-se sobre um conjunto composto de 6 imagens, as quais foram submetidas à contagem manual para a criação de um ground truth. $\mathrm{O}$ primeiro método apresentou, segundo os autores, erro médio de $6,66 \%$, enquanto as demais abordagens apresentaram erro de $7,33 \%$ e $7,84 \%$ para o limiar fixo e usando o $\mathrm{K}$-means, respectivamente.

$\mathrm{O}$ método de contagem automática proposto por Portela et al. (2009) trabalha sobre imagens de dimensões 3072 x 2304 pixels em formato RGB e com resolução de 700 dpi. Cada imagem capturada é dividida em 6 sub-imagens, as quais têm seu número de ovos de Aedes contados manualmente por um especialista. Esta contagem é realizada com auxílio de lentes de aumento.

$O$ primeiro passo do método consiste na conversação do sistema de cores original (RBG) para o formato L*a*b*3 (Luminosidade, coordenada vermelho/verde, coordenada amarelo/azul). Depois de convertida a imagem é submetida a um método de agrupamento (Kmeans) com três clusters e um limite de 100 épocas para convergência. Os grupos formados representam os ovos, o fundo e um conjunto indefinido. Para a formação dos agrupamentos adotou-se os canais a* e $\mathrm{b}^{*}$

Em seguida a imagem original (RGB) é convertida para o formato HSV, focando-se no canal H. Para cada um dos clusters formados pelo $\mathrm{K}$-means calcula-se o valor médio para o canal $\mathrm{H}$. Aquele cluster que apresentar média inferior a 0,5 é descartado e os demais são analisados por possivelmente conterem ovos.

Visando eliminar grupos que representam ruídos o passo seguinte é a análise de componentes conectados. Os conjuntos que possuem menos do que 140 pixels são considerados ruídos e, portanto, descartados. No processo de contagem então, todos os clusters restantes têm seu tamanho dividido pelo tamanho médio de um ovo (357, valor definido empiricamente).

A validação deu-se sobre um conjunto composto por 6 imagens. Houve casos em que o valor estimado apresentou erro de $45,45 \%$ e casos onde conseguiu acertar o valor exato (imagem sem a presença de ovos). 0 erro médio apresentado para o conjunto foi de $6,03 \%$.

No método de contagem apresentado no trabalho de Mello et al. (2009) foram utilizadas imagens com

30 sistema $\mathrm{L} * \mathrm{a} * \mathrm{~b} *$ foi criado com base na teoria de cores opostas, onde duas cores não podem ser verdes e vermelhas simultaneamente, ou amarelas e azuis ao mesmo tempo 
resolução de 700 dpi, obtidas através de uma câmera digital com zoom ótico de 4x. As objetivas capturadas, em formato RGB true color, têm dimensões 3072 × 2304 pixels. Segundo os autores, para a pesquisa as imagens foram divididas em segmentos menores. $O$ tamanho destas sub-imagens, no entanto, não é apresentado.

Foram propostas duas estratégias para a contabilização dos ovos do Aedes. Na primeira faz-se, inicialmente a conversão para o sistema de cores HSV, onde focou-se no Hue que foi o que mostrou-se mais discriminante para separar ovos e palheta. Sobre este canal então aplicou-se a limiarização adaptativa proposta por $\mathrm{Hu}-$ ang and Wang (1995).

Após a binarização, os conjuntos de pixels com menos de 100 elementos são descartados (possíveis ruídos). Em seguida a imagem é submetida a uma operação morfológica de fechamento com um elemento estruturante de dimensões $8 \times 13$ pixels. Por fim, os conjuntos conectados têm sua área dividida por um tamanho médio de ovo (170 pixels) para se determinar quantos ovos estão presentes em cada grupo.

Na segunda estratégia proposta a imagem é convertida para o sistema de cores YIQ e o canal I é usado para separar os objetos de interesse do background. Para tanto, foram adotadas duas opções: a primeira usou um limiar fixo em 200 e a segunda empregou o método de agrupamento $\mathrm{K}$-means ( 3 atributos, 4 classes, taxa de aprendizado de 0,1 e com limite de 200 iterações) para realizar a segmentação.

Os experimentos foram validados sobre um conjunto de seis imagens contendo números variados de ovos. Todas as imagens foram submetidas à contagem manual para se obter o padrão ouro de cada uma. O método cuja estimação foi a mais acurada foi a primeira estratégia apresentando, segundo os autores, um erro médio de $6,66 \%$.

Em seu trabalho Silva et al. (2010) desenvolveram um sistema de contagem automática baseado em três etapas. O passo inicial é aplicar uma segmentação por cor de caráter global, eliminando pixels que têm coloração diferente daquela esperada dos ovos. Em seguida é aplicada uma limiarização local, levando em conta janelas de dimensão $100 \times 100$ pixels. Esta fase analisa o histograma do canal vermelho de cada janela e encontra o limiar mais adequado para identificar os pixels de background que têm a colocação mais clara dos pixels dos ovos, que possuem coloração mais escura.

Após a limiarização foi empregado o filtro da moda para remoção de eventuais ruídos, que são pixels identificados erroneamente. Uma vez que os ruídos eram compostos de poucos pixels adotou-se uma máscara de tamanho $3 \times 3$. Assim, elementos menores (ruídos) seriam eliminados e os corpos maiores seriam mantidos.

Na etapa de estimação do número de ovos são contados os pixels presentes em cada grupo classificado como ovo e então divide-se essa contagem pelo tamanho médio estimado para cada ovo. A dimensão adotada foi de 160 pixels.

A avaliação do método proposto foi realizada sobre um conjunto de 58 imagens. Para critério de comparação utilizou-se um groud truth obtido manualmente. Os resultados mostraram uma taxa média de erro de
$16,85 \%$ com desvio padrão de $15,38 \%$.

O primeiro passo do método proposto por Elpídio et al. (2010) foi construir um conjunto de 100 imagens de lâminas de ovitrampas. Estas imagens, de dimensões $512 \times 512$ pixels, foram obtidas posicionando-se uma máscara em uma posição aleatória sobre uma imagem original de tamanho 2300 x 6000 pixels. A ideia de adotar um critério randômico foi tentar diminuir possíveis bias nos dados de entrada.

Visando separar a posição dos ovos do restante da imagem aplicou-se uma técnica de limiarização com threshold único. Para tanto, optou-se pelo canal vermelho, que foi aquele que permitiu uma melhor dicotomia entre região de interesse e background. A imagem resultado foi submetida a dois filtros morfológicos: uma operação de abertura, com elemento estruturante circular de dimensão 5 x 5, seguida de uma operação de fechamento, com elemento estruturante circular de tamanho $7 \times 7$.

Para efetuar a contagem dos ovos todos os conjuntos de pixels foram rotulados em quatro grupos: regiões compostas por 3 ovos, regiões compostas por 2 ovos e regiões que representam apenas um ovo. Caso contrário o grupo é classificado como ruído e não entra na contagem.

Na etapa de avaliação do método, três pesquisadores contaram manualmente o número de ovos presentes em cada imagem. O valor adotado como ground truth para cada imagem foi a média das três contagens. A validação, realizada aplicando-se o método dos erros médios quadráticos, apontou que a contagem obtida pela abordagem automática proposta foi muito similar à contagem manual. No entanto, os autores indicam a necessidade de estratégias mais precisas para tratar regiões compostas por mais de um ovo, principalmente em casos em que ocorre a sobreposição dos mesmos.

O Sistema Autônomo de Reconhecimento e Contagem de Ovos (SARPO) proposto por Tiba et al. (2011) trabalha com imagens escaneadas com resolução de 2400 dpi e dimensões 11000 x 5000 pixels. Estas imagens continham registros de placas em perfeito estado mas também de lâminas empenadas ou sujas devido às condições a que foram expostas. Tal cenário serviu para avaliar a robustez da ferramenta desenvolvida. Segundo os autores foram digitalizadas cerca de 300 palhetas, divididas uniformemente em três grupos de acordo com a densidade: baixa (menos de 300 ovos), média (de 300 a 600 ovos) e alta (aqueles com mais de 600 ovos presentes). Das 300 imagens foram selecionadas 18 para validação dos métodos, sendo 6 de cada grupo de densidade.

Devido ao tamanho considerável das imagens de entrada estas foram divididas em blocos de tamanho 800 x 550 pixels. Cada imagem foi subdividida em aproximadamente 140 blocos. Tais blocos são então levados à etapa de segmentação onde foram adotados dois modelos usando redes neurais. O primeiro utiliza um MLP (Perceptron de Múltiplas Camadas, do inglês, Multilayer Perceptron) para quantizar a imagem para tons de cinza e definir se um pixel faz parte de um ovo ou se é fundo da imagem. A segunda rede neural além de realizar a quantização para tons de cinza faz ainda a aplicação 
de remoção de ruídos antes da classificação dos pixels. Para tanto, adota dois MLPs de forma sequencial. A função de ativação adotada foi a tangente hiperbólica.

Para cada pixel é construído um vetor de características com 9 posições. As informações extraídas de cada pixel são as médias dos canais $\mathrm{R}, \mathrm{G}$ e $\mathrm{B}$ em uma vizinhança de $3 \times 3$ centralizada no pixel em análise. Além disso são extraídas as médias dos canais $R, G$ e $B$ bem como os desvios padrão de cada canal dentro de uma área circular centralizada no pixel em foco. Além das 9 características, informou-se se a classe do pixel (fundo ou ovo). Quando a imagem estava em tons de cinza eram levantadas apenas 3 informações, uma vez que os três canais são iguais.

$\mathrm{O}$ treinamento supervisionado das redes foi composto de 100 imagens de tamanho $100 \times 100$ pixels retiradas 18 imagens selecionadas para avaliação da ferramenta. Dessas 100 imagens foram obtidos 9000 registros de pixels para o aprendizado das redes. Dentro das amostras, $80 \%$ representam pixels do fundo enquanto apenas $20 \%$ correspondem a pixels de ovos. 0 treino recebeu 6750 amostras, já o conjunto de validação englobou as 2250 amostras restantes.

A etapa de contagem aplica um limiar na imagem de saída das redes neurais para determinar se cada pixel é fundo ou compõe um ovo. Em seguida são identificados os grupos de pixels conectados e que representam ovos. O tamanho desses grupos é dividido por um valor médio para se determinar o número de ovos presentes no conjunto. Este valor médio foi obtido através da média da estimação dada por três especialistas.

A avaliação foi realizada sobre o conjunto de $18 \mathrm{ima-}$ gens separadas inicialmente. Para se construir um padrão ouro, tais imagens foram submetidas à contagem manual dos ovos presentes em cada palheta. Além disso os autores compararam os resultados com um processo de segmentação manual e com a contagem assistida por microscópio. O teste de Lilliefors não rejeitou a hipótese nula ao comparar-se todos os métodos em conjunto. A comparação par a par dos métodos, no entanto, mostrou que a segmentação manual e a solução proposta foram aquelas que mais se aproximaram dos valores ideais, apresentando erro percentual médio de $1,87 \%$ e $4,9 \%$, respectivamente.

Em seu trabalho, Elpídio et al. (2011) propuseram uma evolução da estratégia apresentada em (Elpídio et al., 2010). Nesta abordagem adotou-se a quantização para tons de cinza antes da binarização da imagem, diminuindo assim a gama de cores do conjunto antes de tentar identificar fundo e regiões de interesse.

Após o processo de segmentação da imagem é aplicada uma rede neural artificial (MLP) para classificar se um determinado conjunto de pixels consiste de fundo da imagem ou se compõe um ou mais ovos. Para tomar tal decisão o MLP usa informações como o tamanho médio do ovo, a área da região em análise, entre outros. Não são apresentados detalhes de configuração do MLP e nem como é feita a ponderação dos canais RGB no momento da quantização para tons de cinza.

No estudo foram adotadas 30 imagens de dimensões 2300 x 6000 pixels. Essas imagens foram submetidas a um processo randômico de amostragem que gera sub-imagens de tamanho $512 \times 512$ pixels. Os autores não apresentam o número de sub-imagens geradas e usadas na pesquisa.

Os resultados mostraram que as contagens realizadas de forma automática foram muito similares às obtidas de forma manual, com auxílio de técnicos especializados. Segundo os autores a contagem conseguiu acertar a decisão entre ovo e palheta em $94 \%$ dos casos testados.

O trabalho apresentado por Silva et al. (2011) é bastante similar àquele publicado por Silva et al. (2010). Inicialmente realiza-se a captura das imagens utilizando-se uma arquitetura própria, específica para a função. As imagens de ovitrampas capturadas têm dimensões $5071 \times 2304$ pixels.

Essas imagens são então disponibilizadas na interface do software que permite ao usuário escolher entre a contagem assistida ou totalmente automática. $\mathrm{Na}$ primeira opção, ele pode contar manualmente os ovos presentes na imagem e ir marcando a posição dos mesmos através do clique do mouse. Para tanto, o sistema oferece mecanismos de zoom e movimentação da imagem, além de destacar os pontos já computados.

Os experimentos mostraram que o consumo de tempo da abordagem assistida é duas vezes menor do que a contagem com auxílio de lentes de aumento. Além disso, ao se comparar o tempo gasto pela contagem manual clássica com o método automático, a discrepância de tempo consumido é ainda maior. Em termos de precisão na contagem dos ovos, a abordagem assistida contou, em um conjunto de 100 palhetas, um total de 3297 ovos. A abordagem automática identificou a presença de 3385 ovos nas mesmas 100 palhetas, obtendo, segundo os autores, um erro de apenas $2,67 \%$.

No trabalho de Silva et al. (2012) se propõe um sistema de hardware para aquisição de imagens, um sistema de contagem semiautomático assistido, uma interface homem-máquina e um sistema de contagem automática dos ovos. As informações obtidas são enviadas pela Internet para um servidor WEB. A contagem automática baseia-se nos processos: segmentação, filtragem e contagem.

A etapa de segmentação é executada em duas fases. Na primeira, aplica-se uma segmentação por cor de caráter global. Nesta fase foram analisados os histogramas dos canais $\mathrm{R}, \mathrm{G}$ e B e, aqueles pixels que atenderam às duas regras construídas, eram considerados como ovos e os demais eram rotulados como pixels de fundo. A segunda fase da segmentação tem caráter local. Nela são aplicadas máscaras de dimensões $100 \times 100$ e as informações analisadas localmente. Neste contexto um histograma local é construído e um limiar adaptável é obtido segundo critérios definidos com base na distribuição das frequências, muito similar à distribuição gaussiana. Os experimentos mostraram que o canal vermelho é o mais indicado para tal análise. Assim, para cada janela se obtém um limiar que serve de divisa entre o que é fundo e o que é ovo. Valores maiores que o limiar são considerados corpo da palheta enquanto valor menores indicam a presença de ovos do Aedes.

Eventuais pixels classificados erroneamente serão corrigidos com a aplicação dos filtros espacial e morfo- 
lógico na sequência. $\mathrm{O}$ filtro espacial adotado foi o da moda, com uma máscara de tamanho $3 \times 3$. Já para a abordagem morfológica empregou-se uma operação de abertura com elemento estruturante circular de raio 2 .

A etapa final do processo consiste da própria contagem dos ovos. Nesta fase, os conjuntos de pixels classificados como ovos são contados e divididos pelo tamanho médio de um ovo identificado empiricamente pelos pesquisadores.

A solução semiautomática mostrou-se três vezes mais rápida do que a contagem manual assistida por lupa ou microscópio. Visando avaliar o desempenho em termos de estimação do número de ovos foi utilizado um conjunto composto por 100 imagens de palhetas de ovitrampas. Os resultados mostraram um erro médio de $16,26 \%$ para o conjunto todo em comparação à contagem manual, resultado considerado satisfatório pelos autores, dada a complexidade da tarefa.

Duas estratégias de contagem foram propostas no trabalho de Feitosa (2015). Na primeira abordagem aplicou-se uma normalização dos pixels no canal vermelho e, em seguida a limiarização de Otsu neste mesmo canal. Na sequência aplicou-se uma operação morfológica de abertura para remoção de ruídos e a análise dos componentes conectados para determinar o número de ovos presentes na imagem. A segunda abordagem converte a imagem para o sistema $L^{*} a * b *$ e aplica o método de $\mathrm{K}$-means sobre os canais $\mathrm{a} * \mathrm{e} \mathrm{b*}$ para identificar pixels que podem ser ovos e pixels de devem pertencer ao fundo da imagem.

A validação deu-se sobre dois conjuntos compostos por 5 imagens (a primeiro conjunto, mais simples continha 33 ovos enquanto o segundo conjunto totalizou 190 ovos). O primeiro método de contagem, testado sobre o conjunto 1 levou a um erro médio absoluto de $24,03 \%$. A segunda estratégia, testada no conjunto 2 , apresentou uma taxa de erro média de $17,02 \%$.

$\mathrm{Na}$ estratégia para contagem de ovos proposta por Morais et al. (2015) desenvolveu-se um hardware para captura das imagens de ovitrampas. Tal estrutura é composta de uma câmera instalada em um braço com dois graus de liberdade, de forma a permitir o posicionamento correto da câmera sobre as lâminas de ovitrampas.

Após a etapa de captura da imagem a mesma é submetida a um processo de limiarização cujo objetivo é separar a informação visual em duas classes, fundo da imagem e objeto de interesse (ovos). Neste cenário, os ovos do mosquito têm coloração mais escura que da lâmina, permitindo assim a sua identificação. Com a imagem segmentada faz-se a estimação do número de ovos em cada grupo de pixels dividindo sua área pelo tamanho médio de cada ovo.

Para a avaliação do framework proposto foram empregadas 4 imagens de lâminas de ovitrampas. Cada imagem foi submetida à contagem manual de forma a se saber exatamente a quantidade de ovos presentes em cada cenário. Os testes mostraram que o método conseguiu uma taxa de erro de $0,4 \%$ no melhor caso e de aproximadamente $8 \%$ no pior cenário. Os experimentos mostraram que o desempenho foi superior nas imagens com maior presença de ovos.
Uma plataforma web é proposta por Brasil et al. (2015), onde são combinadas estratégias de contagem automática de ovos de Aedes com sistemas de informação geográfica. O processo de contagem é divido nas etapas de segmentação dos objetos de interesse, operações morfológicas de dilatação e erosão, expansão e contagem. Os detalhes da estratégia de contagem é aquela apresentada em Morais et al. (2014).

Para configuração das dimensões das imagens a serem adotadas na ferramenta desenvolvida para contagem automática foram testados 50 imagens de lâminas com 3 tamanhos diferentes. Seus resultados foram comparados à contagem manual. Os autores propuseram a adoção de imagens de 400 x 160, 400 x 250 e 550 x 250 pixels. Através do teste de Wilcoxon observou-se que não houve diferença significativa entre a contagem manual e contagem automática realizada sobre as imagens de dimensão 400 x 250 pixels. Entretanto, a diferença para os outros dois tamanhos foi considerada significativa. Assim, a escolha deu-se pelo tamanho de 400 linhas por 250 colunas.

O software ICount, desenvolvido por Gaburro et al. (2016), consiste de uma ferramenta computacional para a contagem semiautomática e automática dos ovos do Aedes. Durante o processo é realiza uma operação de segmentação com o objetivo de identificar o que é fundo e o que são ovos. Para tanto, adota-se um limiar previamente estabelecido, mas que pode ser definido pelo usuário.

Após segmentada, a imagem é submetida ao processo de contagem. Nesta etapa os conjuntos de pixels que representam os objetos de interesse são contabilizados e, de acordo com o tamanho desses conjuntos estimase a quantidade de ovos presentes em cada um. Para tanto, são adotados limiares mínimos e máximos para o número de pixels que compõe cada ovo. Esses limites podem seguir valores default ou serem definidos pelo usuário.

A avaliação da ferramenta deu-se sobre dois conjuntos de imagens. O primeiro, macro (obtido via câmera fotográfica), envolve imagens mais afastadas em que os ovos têm dimensão menor e o segundo conjunto, micro (obtido com microscópio com zoom de 8x), em que os ovos têm tamanhos maiores. 0 conjunto de validação era composto por 48 imagens macro e 380 imagens micro.

Visando construir o padrão ouro, cada imagem micro foi submetida à contagem manual. Já as imagens macro, foram submetidas a um software de contagem chamado Cell Counter (Schneider et al., 2012).

As contagens apontaram uma configuração de três grupos: imagens com baixa densidade de ovos, imagens com média e alta densidade.

Uma análise regressiva mostrou que não houve diferença significativa entre a contagem manual e aquela obtida pelo ICount. No entanto, ao analisar-se o tempo gasto, a solução proposta (automática) foi até 19 vezes mais rápida que a abordagem manual. A solução, no entanto, demanda que o fundo claro tenha um bom contraste com os ovos, de cor mais escura. Além disso, segundo os autores, o sistema não lida bem com cenários de sobreposição de ovos. 
Em seu trabalho Alves (2016) desenvolveu um sistema de baixo custo para captura e contagem automática de ovos de Aedes em imagens de ovitrampas. Durante a construção do framework considerou-se a possibilidade de adoção das palhetas constituídas de eucatex ou de lâminas de algodão.

Para a etapa de captura foi desenvolvida uma estrutura em formato de caixa com o objetivo de criar um ambiente homogêneo adequado para a aquisição das imagens. Para tanto, adotou-se um celular como mecanismo de captura, com resolução de $13 \mathrm{MP}$.

$\mathrm{Na}$ etapa de contagem o primeiro passo realizado é a binarização sobre o canal vermelho do sistema RGB. Após experimentos verificou-se que ele fornecia a maior discrepância entre os ovos e os demais objetos da cena. Esta binarização, executada de forma manual, sugere um limiar igual a 90 que foi o valor que mostrou-se mais apropriado.

Em seguida é aplicada uma nova operação de limiarização, agora de forma automática, sobre o canal azul. O patamar adotado foi 180 , valor identificado como 0 mais adequado à segmentação.

A análise dos componentes conectados é o passo seguinte da contagem. Neste momento é estimada a quantidade de ovos presentes em cada conjunto de pixels de acordo com um tamanho previamente estimado pelo pesquisador. $\mathrm{O}$ tamanho médio dos filtros adotados na contagem variou entre a palheta de madeira e o algodão, isso porque as superfícies têm características distintas que influenciam na visualização dos ovos.

Os testes de validação foram realizados sobre dois conjuntos distintos. O primeiro, contendo apenas imagens de palhetas, era composto de 48 imagens. Já o segundo era constituído de 30 imagens de algodões contendo ovos do mosquito. Para cada uma das 78 imagens fez-se a contagem manual para se conhecer a quantidade real de ovos presentes.

A avaliação do desempenho da contagem dos ovos nas 48 palhetas indicou um erro de $6,8703 \%$ em relação a média estimada para a média real. Observou-se um desvio padrão de $36,7388 \%$. Já para as 38 imagens de algodão o erro diminuiu para $0,9436 \%$ considerando a média estimada perante a média real. 0 desvio padrão também apresentou um valor inferior, 19,3279\%, indicando que o método foi mais acurado neste cenário e apresentou menor variabilidade.

Na estratégia de contagem automática desenvolvida por Rizzi et al. (2016), realiza-se a segmentação entre corpo de fundo e ovos. Para tanto, fez-se a conversão do sistema RGB para o HSV e aplicou-se um limiar fixo sobre o canal $\mathrm{H}$ para determinar se cada pixel seria fundo ou objeto de interesse. Todavia, as imagens apresentavam variações consideráveis na coloração dos ovos, principalmente devido ao brilho presente na superfície dos mesmos.

A estratégia adotada para contornar o problema foi a construção de um sistema especialista que armazenava todos os pixels classificados corretamente como ovos. No momento da segmentação de uma nova imagem, caso houvesse novos erros (em decorrência da reflexão de luz) os pixels poderiam ser identificados pelo usuário como ovos e o sistema aprenderia que, dadas aquelas características, o pixel deveria fazer parte do conjunto de interesse.

Em seguida foram analisadas as dimensões dos componentes conectados. Para se estimar a quantidade de ovos presentes em cada grupo de pixels, dividiu-se a área ocupada pelo grupo por um tamanho médio previamente calculado pelos pesquisadores. A validação do método foi realizada sobre um conjunto composto por 5 imagens, as quais foram submetidas à contagem manual de forma a formar seu ground truth. Em seguida, fez-se a contagem automática do número de ovos presentes em cada imagem e comparou-se com o valor esperado. Os resultados indicaram uma erro médio absoluto de 27,01\%.

Uma abordagem utilizando lógica fuzzy foi empregada na solução proposta por Costa (2017). Nela, uma imagem é convertida para tons de cinza e então segmentada, separando os ovos do background. A bounding-box de cada ovo é então obtida e informações acerca de cada ovo são extraídas, como a quantidade de pixels que compõe o ovo, a convexidade do mesmo, a quantidade de pixels no perímetro do objeto e a relação comprimento por largura do ovo. Tais informações são usadas para calibrar o classificador para que o mesmo seja capaz de identificar com sucesso os ovos do mosquito.

O conjunto de validação utilizado foi composto de 206 imagens que continham 7772 objetos, dos quais apenas 386 eram ovos do Aedes. A acurácia do classificador foi de $98,98 \%$, com uma especifidade de $99,8 \%$ e sensibilidade de $85,4 \%$.

No trabalho apresentado por Yussof e demais pesquisadores (Wan Yussof et al., 2018) se propôs a adoção de um filtro de Gabor para otimizar o processo de limiarização da imagem, fazendo com que a segmentação dos ovos do Aedes fosse mais eficiente. A ideia dos autores foi adotar o filtro com o objetivo de realçar a diferença entre os ovos do mosquito e o fundo das imagens. Além disso, outro objetivo foi que o processo fosse todo automático, sem a definição de parâmetros por conta do usuário.

Posteriormente à filtragem da imagem é aplicada a limiarização de Otsu (1979). Com a imagem binarizada são aplicadas as operações morfológicas de abertura e dilatação. Em seguida são analisados os elementos caracterizados como ovos visando a contagem dos mesmos. Objetos compostos por mais de 100 pixels são considerados ovos. No entanto, caso sejam observadas regiões com comportamento não elíptico, o software considera que há uma área de sobreposição de ovos e tenta estimar o número de elementos presentes naquele grupo, levando em conta do tamanho médio considerado para cada ovo individualmente.

A validação deu-se em dois conjuntos de imagens. O primeiro, usando imagens macro das lâminas de ovitrampas, era composto de 5 imagens. Já o segundo conjunto envolvia 5 imagens micro de ovitrampas. Para critério de comparação efetuou-se a contagem manual das lâminas visando criar o ground truth para avaliação dos métodos. Além disso, submeteu-se as mesmas imagens à contagem através do software ICount (Gaburro et al., 2016).

Para as imagens macro, que contém informações 
globais das imagens, os resultados da estratégia proposta apresentaram erro variando de $1 \%$ a $4 \%$. Já para as imagens micro, onde a presença dos ovos é mais evidente, o método apresentado obteve $100 \%$ de acerto, conseguindo contar exatamente o número de ovos presentes nas imagens de ovitrampas.

A estratégia para contagem automática proposta por Garcia et al. (2019) emprega técnicas de processamento de imagens combinadas com métodos de Aprendizagem de Máquina para obter a estimação mais precisa possível. A proposta adota uma mecanismo de classificação estruturado de forma sequencial onde inicialmente empregou-se um classificador baseado em árvore de decisão e, em seguida, uma rede neural convolucional (CNN).

As imagens empregadas na pesquisa foram obtidas através de uma câmera com 40x de zoom ótico. Ao todo foram obtidas 425 imagens em formato RGB e com dimensões $3000 \times 4000$ pixels. No momento da execução do experimento, no entanto, foram utilizadas apenas 360 imagens ( 300 para treino, 30 para validação e 30 para teste). Imagens sem a presença de ovos foram desconsideradas.

A primeira etapa do processamento é remover das imagens, regiões que não fazem parte da palheta em decorrência do processo de captura. Em seguida, são extraídas as informações para o treinamento do primeiro classificador (árvore de decisão). Para formar o vetor de características de cada pixel extraiu-se os canais R, G e B da imagem, bem como os canais L, a e b do sistema $\mathrm{L}^{*} \mathrm{a} * \mathrm{~b} *$. Além dos seis atributos armazenou-se também se o pixel era ovo ou palheta.

As imagens obtidas após o primeiro classificador são binárias, indicando a presença ou ausência de ovos em cada pixel. As regiões de ovos com um tamanho inferior a um limiar foram consideradas como fundo da imagem. Esta imagem então é fornecida como entrada para a CNN para treinamento da rede.

Para a avaliação dos resultados adotou-se o coeficiente de correlação de Pearson onde comparou-se, para cada uma das 30 imagens, a quantidade de ovos contada manualmente perante o número de ovos estimados pelo sistema. Os primeiros resultados apontaram para uma correlação de 0,86 entre os valores reais e estimados. Removendo-se as imagens com presença de corpos estranhos, como insetos, ovos de outros insetos, a correlação alcançada foi de 0,9703 .

Uma estratégia de aprendizagem de máquina é adotada por Rocha et al. (2019). A imagem de entrada é submetida a um filtro de realce (high-boost) e em seguida serve de entrada ao algoritmo Haar Cascade. Esta técnica utiliza um conjunto de classificadores em forma de castata, onde os primeiros são mais generalistas e os finais são os mais apurados. O método visou classificar se uma determinada região é ou não um ovo de Aedes.

Para o treinamento dos classificadores foram utilizados 720 segmentos de imagens contendo ovos do mosquito (casos positivos) e 1440 sub imagens sem a presença de ovos (casos negativos).

A imagem utilizada na validação do método continha 26 ovos do Aedes, dos quais 14 foram identificados com sucesso pela solução proposta (taxa de recall pró- xima de $60 \%$ ). O número de falsos positivos não foi apresentado.

No trabalho de Santana Jr et al. (2019) desenvolveuse uma arquitetura para aquisição de imagens de palhetas de ovitrampas e também uma estratégia para contagem automática dos ovos presentes nas palhetas.

O sistema captura imagens com resolução de $2 \mathrm{MP}$ e as envia a um servidor onde as mesmas são contadas pelo sistema desenvolvido. O processo de aquisição é feito percorrendo-se as palhetas e armazenando segmentos do objeto como um todo. A dimensão das imagens capturadas não foi divulgada no trabalho. Depois de armazenadas as imagens são fornecidas ao módulo de contagem.

O método de reconhecimento é baseado em uma rede neural convolucional em que adotou-se o modelo R-FCN (do inglês, Region-based Fully Convolutional Networks) e a API para detecção de objetos TensonFlow (Huang et al., 2017). A rede foi treinada para aprender o que eram os ovos do mosquito visando identificá-los e então realizar a contagem.

A avaliação da estratégia de contagem contou com um conjunto de 984 imagens, das quais 787 foram empregadas no treinamento da rede neural e as 197 imagens restantes foram usadas para medir a precisão do modelo. Todas as imagens foram, inicialmente, submetidas à contagem e rotulação manual dos ovos presentes.

Em comparação a duas estratégias presentes na literatura, a solução proposta mostrou-se mais acurada, conseguindo identificar e contar com precisão $91 \%$ dos ovos presentes. O teste não paramétrico de Wilcoxon, segundo os autores, não mostrou diferença significativa entre a contagem manual e a contagem automática através da rede neural convolucional utilizada, considerando uma significância de $5 \%$.

Além dos trabalhos supracitados há ainda diversas obras na literatura que podem contribuir para o desenvolvimento e escolha de técnicas para contagem de ovos de Aedes. Dentre as quais podemos citar a pesquisas de Mollahosseini et al. (2012) que realiza a contagem de ovos de Anopheles, o trabalho de Barbedo (2013) em que realiza a contagem semi-automática de objetos. Pode-se mencionar a técnica de contagem automática de ovos de carrapato proposta por Paiva et al. (2016), a proposta de contagem automática de ovos de Drosophila apresentada por Waithe et al. (2015), bem como o trabalho de Al-Saaidah et al. (2018) em que desenvolveu-se uma técnica para contagem automática de ovos de peixe-zebra, entre outras.

\section{Compilação dos dados}

Ao compilarmos os trabalhos selecionados na literatura levantamos quais as técnicas de processamento de imagens foram mais aplicadas. Como esperado, a segmentação foi amplamente utilizada uma vez que visa separar os pixels que compõe as palhetas do conjunto de pixels que representam os ovos. O processo realizado, no entanto, variou de trabalho a trabalho. Foram empregadas a limiarização simples com base em patamar único ou com patamar adaptativo (Otsu), a 
segmentação com base em regras pré-definidas (sobre os canais dos sistemas de cores) e segmentação assistida por técnicas de Aprendizagem de Máquina (Árvore de Decisão e K-means). Além disso, observou-se a aplicação da limiarização sobre informações globais, geralmente sobre um dos canais de cores, e a segmentação local, em que era definida uma janela deslizante para a estimação do limiar na vizinhança do pixel em análise.

Em alguns casos, para que a limiarização fosse mais efetiva fez-se, inicialmente a quantização da imagem colorida para tons de cinza. Para realizar o processo, aplicou-se um conjunto de equações que atribui um peso a cada canal do sistema de cores ou através de métodos inteligentes (MLP e K-means).

Com relação aos sistemas de cores observou-se que o RGB foi o mais empregado entre as abordagens estudadas. No entanto, em diversos trabalhos adotou-se a conversão entre os sistemas de cores. A ideia principal foi o de tentar encontrar uma representação que permitisse uma melhor separação entre backgroung e foreground. Para tanto, foram adotados também os sistemas de cores HSV, YIQ e L*a*b*.

Depois de binarizada a imagem, em alguns trabalhos optou-se por aplicar algum tipo de filtro para a remoção de eventuais ruídos, ou seja, conjuntos de pixels que poderiam ser confundidos com ovos. Alguns trabalhos permitiam ao usuário a decisão de descartar manualmente eventuais ruídos. No entanto, na maioria das pesquisas adotou-se filtros como a moda ou operadores morfológicos, como abertura e fechamento. Além disso, em algumas pesquisas, adotou-se um limiar de tamanho que, se não alcançando pelo grupo de pixels, ele seria descartado.

No processo de estimação do número de ovos presentes em cada imagem, grande parte dos trabalhos adotou a análise de componentes conectados. A tarefa consiste em percorrer a imagem encontrando grupos de pixels pretos que são vizinhos e, portanto, fazem parte do mesmo grupo. Normalmente, após identificados os grupos, comparava-se o tamanho desses com algum limiar pré conhecido. Caso o tamanho do conjunto fosse muito pequeno, ele era desconsiderado, caso contrário, ele poderia conter um ou mais ovos do Aedes. De forma geral o tamanho dos grupos era divido por um tamanho médio dos ovos conhecido a priori para se saber 0 número de ovos presentes no conjunto.

Algumas pesquisas utilizam estratégias de Aprendizagem de Máquina para tentar realizar os processos da forma mais automática possível e buscando a maior precisão na contagem dos ovos. Tais técnicas foram empregadas em duas oportunidades:

- Na segmentação das imagens (quantização para tons de cinza e binarização), usando os método de Árvores de decisão, MLP e K-means;

- Na classificação de um conjunto de pixels como sendo ou não um ovo através de técnicas de Deep Learning (redes CNN's e R-FCN).

A presença de uma gama tão diversa de técnicas para o processamento das imagens, análise das informações e contagem dos ovos se deve à grande variabilidade de características das imagens em estudo, uma vez que cada técnica ou parâmetro pode funcionar melhor para um cenário, mas não ter um desempenho tão preciso em outros. A Fig. 2 ilustra bem a variabilidade que pode ser encontrada dentre as obras levantadas. Na imagem é possível perceber a grande discrepância em termos de coloração, resolução e qualidade na captura.

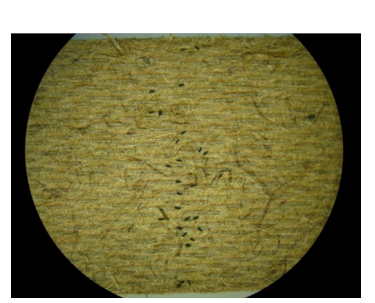

(a) Garcia et al. (2019)

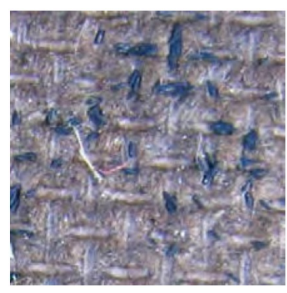

(c) Silva et al. (2010)

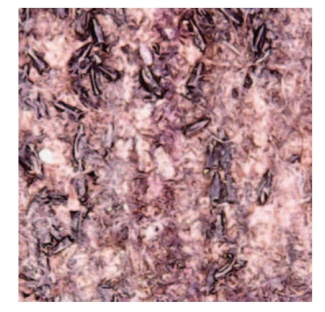

(b) Santana Jr et al. (2019)

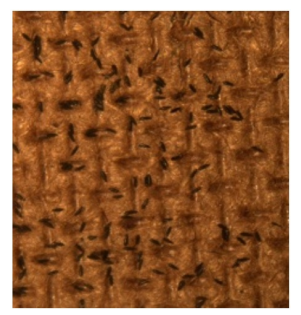

(d) Alves (2016)

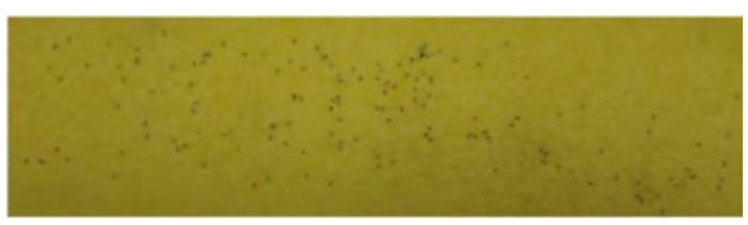

(e) Wan Yussof et al. (2018)

Figura 2: Exemplos de imagens de ovitrampas adotadas nos estudos levantados.

Visando compilar as informações levantadas nas obras presentes na literatura, construímos uma tabela resumindo detalhes de cada pesquisa. Os dados são apresentados nas Tabelas 1 e 2. Na primeira coluna são identificadas as obras. Em seguida, para cada trabalho, são listadas as operações de processamento de imagens aplicadas. Na terceira coluna são apresentados os cenários em que os experimentos foram realizados, identificando o número de casos analisados. Nos estudos foram empregados imagens parciais de palhetas de ovitrampas, imagens completas de palhetas e imagens de lâminas de algodão.

Na quarta coluna são apresentadas métricas para a avaliação do desempenho das estratégias propostas. Em alguns trabalhos não foram informados os dados que representam o padrão ouro de contagem dos ovos nas imagens e nem os valores estimados pelos métodos. Para tais pesquisas apresentou-se as medidas descritas 
nos trabalhos. Entre as métricas citadas foram adotadas a correlação (representada pela variável $\mathrm{R}$ nas Tabelas 1 e 2) e o erro médio quadrático (EMQ). Além disso, há o trabalho de Brasil et al. (2015) em que fezse a comparação das médias dos métodos propostos perante a média da contagem manual para identificar qual estratégia seria a mais adequada.

Para os trabalhos em que tais informações foram apresentadas, buscou-se criar uma representação padrão para todas. Neste intuito, utilizamos a métrica aqui chama de erro médio (EM). A forma com que o índice é calculado é ilustrada na Tabela 3 através de valores fictícios.

Na tabela são apresentados o padrão ouro de cada imagem (Valor Real), a quantidade estimada pela técnica (Valor Estimado) e o erro encontrado. Neste caso, consideramos que uma superestimação ou subestimação têm o mesmo peso e, para tanto, o erro foi considerado como valor absoluto. O erro percentual (\% Erro) então é calculado dividindo-se o erro pelo Valor Real de cada imagem.

A ideia de calcular o erro percentual para cada imagem deu-se para tentar levar em conta o peso do número de ovos presentes em uma imagem. Por exemplo, o erro observado na contagem para a terceira imagem é de 9 ovos, o que representa $2,65 \%$ do total de ovos presentes na imagem. Para a quinta imagem, no entanto, o erro na contagem é de apenas 4 unidades. Entretanto, como o número de ovos presentes na imagem é de apenas 15 unidades, o peso do erro, neste caso, é muito superior ao observado para a terceira imagem. Neste caso, o erro seria de $26,67 \%$.

Para obtermos então o erro médio do método ilustrado na Tabela 3 basta calcularmos a média entre os erros percentuais de todas as imagens do conjunto. Dessa forma, o valor de EM seria de $9,09 \%$, ou seja, o método pôde estimar o número de ovos com precisão de $90,91 \%$.

Além das técnicas de processamento de imagens foram identificadas as estratégias de aprendizagem adotadas na contagem dos ovos de Aedes, as quais são apresentadas na Tabela 4, especificadas por trabalho. Observando-se as opções empregadas, nota-se que o algoritmo de agrupamento $\mathrm{K}$-means foi o mais empregado, principalmente para segmentar os pixels das palhetas dos pixels que compõem os ovos. Com o mesmo objetivo foram utilizadas também as técnicas MLP, Árvore de Decisão e um sistema especialista que, apesar de não ser um método de aprendizagem de máquina, foi usado no trabalho de Rizzi et al. (2016) como um método de aprendizagem por reforço. Além disso, observou-se a adoção de estratégias mais robustas, visando a construção de uma ferramenta de contagem mais independente das características das imagens. Tal fato foi verificado nas obras de Garcia et al. (2019) e Santana Jr et al. (2019) onde adotou-se métodos de aprendizado profundo para o reconhecimento e contagem dos ovos.

Apesar das diferentes características observadas nas imagens de estudo, alguns pontos devem ser levados em conta para que as técnicas de contagem (principalmente aquelas automáticas) tenham sucesso. Espera- se que o processo de captura das imagens das ovitrampas dê-se em um ambiente controlado, com iluminação uniforme que incida com a mesma intensidade sobre toda a lâmina e que não projete sombras. $\mathrm{O}$ hardware usado na captura deve ser de boa qualidade, permitindo um bom nível de aproximação, além de oferecer boa resolução das imagens obtidas.

Como apontado por diversos pesquisadores, há ainda fatores externos que influenciam não só no processo de captura como também na contagem dos ovos do mosquito. Tais fatores podem ser, por exemplo, a presença de ovos de outros insetos na palheta ou mesmo restos de insetos mortos. Além disso há fatores que decorrem da natureza da exposição das ovitrampas que ficam à mercê de intempéries, fazendo com que as palhetas acumulem sujeita ou sofram danos físicos, como o empenamento ou a presença de manchas em sua superfície.

Ao analisarmos os experimentos para avaliação dos métodos propostos pudemos observar que grande parte deles possui conjunto pequeno de imagens de ovitrampas usado para validação. Além disso, ao desenvolver um novo método de contagem, os pesquisadores calibram e desenvolvem suas soluções de acordo com as imagens que têm à disposição. Isso pode fazer com que a estratégia proposta possa não ter o desempenho ideal em cenários distintos.

Uma alternativa interessante seria a criação de uma base compartilhada de imagens de ovitrampas em que os autores poderiam disponibilizar seu conjunto de imagens de forma que outros pesquisadores pudessem usá-las para avaliar o desempenho dos seus métodos. Isso contribuiria para o desenvolvimento de métodos robustos de contagem de ovos, bem como para um combate mais efetivo da dengue, uma vez que soluções computacionais poderiam auxiliar com maior precisão na estimação da população do Aedes.

No guia de gerenciamento de dados publicado pela Comissão Nacional de Energia Nuclear e de autoria de Sayão e Sales (Sayão and Sales, 2015) são apontadas algumas das vantagens no compartilhamento dos dados de pesquisas, no nosso cenário, as imagens de ovitrampas. Segundo os autores, com a disponibilização dos dados levantados aumenta-se a eficiência da pesquisa, evitando a duplicação de esforços, incentiva a investigação e o debate científico, potencializa a inovação e novos usos para os dados, além de possibilitar novas formas de colaboração entre os autores dos dados e usuários das informações. Ainda, segundo os autores, o compartilhamento aumenta o impacto dos dados e a visibilidade dos resultados da pesquisa, além de contribuir para dar os devidos créditos aos criadores dos dados.

\section{Conclusão}

Neste trabalho realizou-se um levantamento bibliográfico acerca dos trabalhos publicados onde foram propostas estratégias para contagem de ovos de Aedes aegypti em imagens de ovitrampas. $\mathrm{O}$ foco consistiu em identificar como cada grupo de pesquisadores enfrentou o problema da contagem assistida por computador, 
Tabela 1: Compilação das informações levantadas a partir das obras presentes na literatura que realizam a contagem de ovos de Aedes (EM = Erro Médio; $\mathrm{R}=$ Coeficiente de Correlação; EMQ = Erro Médio Quadrático).

\begin{tabular}{|c|c|c|c|}
\hline Trabalho & Técnica & Validação & Principais resultados \\
\hline Mains et al. (2008) & $\begin{array}{l}\text { Quantização para tons de cinza } \\
\text { Limiarização simples com um patamar } \\
\text { Análise de componentes conectados }\end{array}$ & $\begin{array}{c}\text { Não } \\
\text { Informado }\end{array}$ & $\begin{array}{l}\mathrm{R}=0,9945 \mathrm{~A} . \text { aegypti } \\
\mathrm{R}=0,9925 \mathrm{~A} . \text { albopictus } \\
\mathrm{R}=0,9783 \mathrm{~A} . \text { polynesiensis }\end{array}$ \\
\hline Mello et al. (2008) & $\begin{array}{l}\text { Conversão do sistema RGB para o sistema HSV } \\
\text { Limiarização adaptativa (no canal H) } \\
\text { Análise de componentes conectados } \\
\text { Conversão do sistema RGB para o sistema YIQ } \\
\text { Limiarização simples no canal I (YIQ) } \\
\text { Operações morfológicas de fechamento }\end{array}$ & 6 imagens & $\begin{array}{l}\mathrm{EM}=8,66 \% \text { Método } 1 \\
\mathrm{EM}=12,64 \% \text { Método } 2 \\
\mathrm{EM}=7,39 \% \text { Método } 3\end{array}$ \\
\hline Santos et al. (2008) & $\begin{array}{l}\text { Conversão do sistema RGB para o sistema YIQ } \\
\text { Limiarização simples no canal I (YIQ) } \\
\text { Análise de componentes conectados } \\
\text { Operações morfológicas de fechamento }\end{array}$ & 6 imagens & $\begin{array}{l}\mathrm{EM}=10,69 \% \text { Método } 1 \\
\mathrm{EM}=7,33 \% \text { Método } 2 \\
\mathrm{EM}=7,84 \% \text { Método } 3\end{array}$ \\
\hline Mello et al. (2009) & $\begin{array}{l}\text { Conversão do sistema RGB para o sistema HSV } \\
\text { Limiarização adaptativa (no canal H) } \\
\text { Análise de componentes conectados } \\
\text { Operações morfológicas de fechamento } \\
\text { Conversão do sistema RGB para o sistema YIQ } \\
\text { Limiarização simples no canal I (YIQ) }\end{array}$ & 6 imagens & $\begin{array}{l}\mathrm{EM}=8,66 \% \text { Método } 1 \\
\mathrm{EM}=12,64 \% \text { Método } 2 \\
\mathrm{EM}=7,39 \% \text { Método } 3\end{array}$ \\
\hline Portela (2009) & $\begin{array}{l}\text { Conversão do sistema RGB para } \mathrm{L}^{*} \mathrm{a} \mathrm{b}^{*} \\
\text { Conversão do sistema RGB para o sistema HSV } \\
\text { Limiarização simples com um patamar } \\
\text { Análise de componentes conectados }\end{array}$ & 6 imagens & $\mathrm{EM}=17,14 \%$ \\
\hline Elpídio et al. (2010) & $\begin{array}{l}\text { Quantização para tons de cinza } \\
\text { Limiarização simples no canal R (RGB) } \\
\text { Abertura e fechamento morfológicos } \\
\text { Análise de componentes conectados }\end{array}$ & $\begin{array}{l}50 \text { imagens } \\
50 \text { imagens }\end{array}$ & $\begin{array}{l}R=0,9298 \text { Base } A \\
R=0,8687 \text { Base } B\end{array}$ \\
\hline Silva et al. (2010) & $\begin{array}{l}\text { Segmentação global com base em regras } \\
\text { Segmentação local no canal R (RGB) } \\
\text { Filtro da moda para remoção de ruídos } \\
\text { Análise de componentes conectados }\end{array}$ & 58 imagens & $E M=16,85 \%$ \\
\hline Elpídio et al. (2011) & $\begin{array}{l}\text { Quantização para tons de cinza } \\
\text { Binarização de limiar único }\end{array}$ & 30 imagens & $E M Q=0,09$ \\
\hline Tiba et al. (2011) & Limiarização simples com um patamar & 18 palhetas & $\begin{array}{l}\mathrm{EM}=13,94 \% \text { SARCO } \mathrm{MS} 1 \\
\mathrm{EM}=9,72 \% \text { SARCO } \mathrm{MS} 2\end{array}$ \\
\hline Silva et al. (2012) & $\begin{array}{l}\text { Segmentação global com base em duas regras } \\
\text { Segmentação local no canal R (RGB) } \\
\text { Filtro da moda para remoção de ruídos } \\
\text { Operação de abertura para remoção dos ruídos } \\
\text { Análise de componentes conectados }\end{array}$ & 100 imagens & $E M=16,26 \%$ \\
\hline Brasil et al. (2015) & $\begin{array}{l}\text { Segmentação de foreground e background } \\
\text { Dilatação e erosão morfológicas }\end{array}$ & 50 imagens & Comparação de médias \\
\hline Feitosa (2015) & $\begin{array}{l}\text { Normalização do histograma no canal R (RGB) } \\
\text { Limiarização de Otsu no canal R (RGB) } \\
\text { Operação morfológica de abertura } \\
\text { Análise de componentes conectados } \\
\text { Conversão do sistema RGB para L*a*b* }\end{array}$ & 5 imagens & $\begin{array}{l}\mathrm{EM}=24,03 \% \text { Método } 1 \\
\mathrm{EM}=17,02 \% \text { Método } 2\end{array}$ \\
\hline Morais et al. (2015) & $\begin{array}{l}\text { Limiarização simples com um patamar } \\
\text { Análise de componentes conectados }\end{array}$ & 4 imagens & $E M=3,89 \%$ \\
\hline Alves (2016) & $\begin{array}{l}\text { Limiarização simples no canal R (RGB) } \\
\text { Limiarização simples no canal B (RGB) } \\
\text { Análise de componentes conectados }\end{array}$ & $\begin{array}{l}48 \text { palhetas } \\
30 \text { algodões }\end{array}$ & $\begin{array}{l}\mathrm{EM}=28,39 \% \\
\mathrm{EM}=15,84 \%\end{array}$ \\
\hline Gaburro et al. (2016) & $\begin{array}{l}\text { Limiarização simples com um patamar } \\
\text { Análise de componentes conectados }\end{array}$ & 48 imagens & $\begin{array}{l}\mathrm{R}=0,9823 \\
\mathrm{R}=0,9823\end{array}$ \\
\hline Rizzi et al. (2016) & $\begin{array}{l}\text { Conversão do sistema RPG para HSV } \\
\text { Limiarização simples no canal H } \\
\text { Análise de componentes conectados }\end{array}$ & 5 imagens & $E M=27,01 \%$ \\
\hline
\end{tabular}


Tabela 2: Compilação das informações levantadas a partir das obras presentes na literatura que realizam a contagem de ovos de Aedes - Parte 2.

\begin{tabular}{|c|c|c|c|}
\hline Trabalho & Técnica & Validação & Principais resultados \\
\hline Costa (2017) & $\begin{array}{l}\text { Equalização para tons de cinza } \\
\text { Limiarização adaptativa baseada em descontinuidade } \\
\text { Segmentação dos ovos e bounding-boxes } \\
\text { Extração de características para treinamento }\end{array}$ & 206 imagens & Acurácia $=98,94 \%$ \\
\hline Wan Yussof et al. (2018) & $\begin{array}{l}\text { Filtros de gabor para realce } \\
\text { Limiarização adaptativa de Otsu } \\
\text { Abertura e dilatação morfológicas } \\
\text { Análise de componentes conectados }\end{array}$ & $\begin{array}{l}5 \text { imagens } \\
5 \text { imagens }\end{array}$ & $\begin{array}{l}\mathrm{EM}=1,49 \% \text { macro } \\
\mathrm{EM}=0 \% \text { micro }\end{array}$ \\
\hline Garcia et al. (2019) & $\begin{array}{l}\text { Segmentação de regiões externas à palheta } \\
\text { Conversão do sistema RGB para } L^{*} a^{*} b^{*}\end{array}$ & $\begin{array}{l}30 \text { imagens } \\
27 \text { imagens }\end{array}$ & $\begin{array}{l}\mathrm{R}=0,86 \\
\mathrm{R}=0,9703\end{array}$ \\
\hline Rocha et al. (2019) & Realce por filtro passa-alta (High-boost) & 1 palheta & Taxa de recall $\approx 60 \%$ \\
\hline Santana Jr et al. (2019) & $\begin{array}{l}\text { Segmentação de regiões externas à palheta } \\
\text { Conversão do sistema RGB para } L^{*} a^{*} b^{*}\end{array}$ & $\begin{array}{l}15 \text { imagens } \\
8 \text { palhetas }\end{array}$ & $\begin{array}{l}\text { EMA }=5,14 \% \\
\text { EMA }=16,2 \%\end{array}$ \\
\hline
\end{tabular}

\begin{tabular}{c|c|c|c}
\hline $\begin{array}{c}\text { Valor } \\
\text { real }\end{array}$ & $\begin{array}{c}\text { Valor } \\
\text { estimado }\end{array}$ & $\begin{array}{c}\text { Erro } \\
\text { absoluto }\end{array}$ & $\%$ Erro \\
\hline 17 & 19 & 2 & 0,1176 \\
23 & 24 & 1 & 0,0435 \\
340 & 331 & 9 & 0,0265 \\
40 & 40 & 0 & 0,0000 \\
15 & 19 & 4 & 0,2667 \\
\hline \multicolumn{4}{c}{ Erro médio (EM) } \\
\hline
\end{tabular}

Tabela 3: Exemplo de como o valor do erro médio (EM) foi calculado.

identificando as particularidades de cada obra.

A análise dos trabalhos apontou que a tarefa consiste em um grande desafio, principalmente dadas às variabilidades a que as imagens estão sujeitas, como resolução, luminosidade, distânncia focal e ruídos. Observou-se que um dos grandes desafios da contagem é escolher uma forma adequada de identificar o que são regiões de ovos e o que é fundo da imagem. Além disso, outro grande passo é caracterizar a quantidade de ovos presentes em conjuntos de pixels, principalmente quanto há certa sobreposição dos ovos.

Espera-se que, com base nas informações levantadas ao longo desta pesquisa, seja possível contribuir para o desenvolvimento de uma ferramenta computacional que seja capaz de lidar com a grande variabilidade de características das imagens de ovitrampas e realizar a contagem automática da melhor forma possível, contribuindo assim para uma estimação precisa do número de vetores nas regiões onde as ovitrampas estiverem posicionadas, fomentando modelos de simulação para o combate efetivo do Aedes na tentativa de diminuir o volume de contágio da dengue.

\section{Referências}

Al-Saaidah, B., Al-Nuaimy, W., Hadidi, m. and Young, I. (2018). Automatic counting system for zebrafish eggs using optical scanner, 2018 9th International Conference on Information and Communication Systems (ICICS), pp. 107-110. https://doi.org/10.1109/IACS.2018.8355450.

Alves, L. D. (2016). Desenvolvimento de um sistema de baixo custo para contagem automática de ovos de Aedes aegypti usando técnicas de processamento de imagens, Mestrado em modelagem matemática da informação, Escola de Matemática Aplicada da Fundação Getúlio Vargas, Rio de Janeiro, Brasil. Disponível em http://hdl.handle.net/10438/16722.

Barbedo, J. (2013). A study on the use of semiautomatic systems for counting objects in digital images, International Journal of Computer and Information Technology 2: 1022-1028. Disponível em https://tinyurl.com/y9vqpt6v.

Brady, O. J., Smith, D. L., Scott, T. W. and Hay, S. I. (2015). Dengue disease outbreak definitions are implicitly variable, Epidemics 11: 92 - 102. https://doi.org/10.1016/j.epidem.2015.03.002.

Brasil, A. (2017). Vacina dengue: esclarecimentos. Disponível em https://tinyurl.com/wwsloto.

Brasil, L., Gomes, M., Miosso, C., Silva, M. and Amvame-Nze, G. (2015). Web platform using digital image processing and geographic information system tools: A brazilian case study on dengue, Biomedical engineering online 14: 69. https://doi.org/10.1186/s12938-015-0052-2.

Brasil, M. d. S. (2020). Guia de gestão de dados de pesquisa para bibliotecários e pesquisadoresmonitoramento dos casos de arboviroses urbanas transmitidas pelo aedes aegypti (dengue, chikungunya e zika), semanas epidemiológicas 1 a 29, 2020, Boletim Epidemiológico 51(31): 1-8. Disponivel em https://www.saude.gov.br/boletinsepidemiologicos.

Costa, E. D. (2017). Desenvolvimento de aplicação computacional para deteç̧ão e contagem de ovos do Aedes aegypti utilizando processamento digital de imagens e lógica fuzzy, Graduação em tecnologias em análise e desenvolvimento de sistemas, Universidade Federal do Rio Grande do Norte, Macaíba, Brasil. Disponível em https://tinyurl.com/y5xqlsze.

Elpídio, F. G., Costa, L. F., Pucci, G. L., Andrade, M., Costa, E. A., Andrade, F. A. and Brasil, M. L. 


\begin{tabular}{l|l}
\hline \multicolumn{1}{c|}{ Trabalho } & \multicolumn{1}{c}{ Técnica de Aprendizagem de Máquina } \\
\hline Mello et al. (2008) & K-means para segmentação entre fundo e objeto de interesse \\
\hline Santos et al. (2008) & K-means para segmentação entre fundo e objeto de interesse \\
\hline Mello et al. (2009) & K-means para segmentaço entre fundo e objeto de interesse \\
\hline Portela (2009) & K-means para segmentação entre fundo e objeto de interesse \\
\hline Elpídio et al. (2011) & Multilayer Perceptron para classificar o que é ou não ovo \\
\hline Tiba et al. (2011) & Multilayer Perceptron para quantização para tons de cinza \\
\hline Feitosa (2015) & K-means para segmentação entre fundo e objeto de interesse \\
\hline Rizzi et al. (2016) & Sistema especialista para aprender com os erros da limiarização \\
\hline Costa (2017) & Sistema Fuzzy para classificar o que é ou não ovo \\
\hline Garcia et al. (2019) & $\begin{array}{l}\text { Árvore de decisão para segmentação do fundo e dos ovos } \\
\text { Convolutional Neural Network (CNN) para reconhecimento dos ovos }\end{array}$ \\
\hline Rocha et al. (2019) & Método Haar-Cascade (Adaboost + Decision Trees) para classificar o que é ou não ovo \\
\hline Santana Jr et al. (2019) & Region-based Fully Convolutional Networks (R-FCN) para reconhecimento dos ovos \\
\hline
\end{tabular}

Tabela 4: Estratégias de aprendizagem empregadas pelos autores para a contagem dos ovos do Aedes.

(2010). Automatic identification of Aedes aegypti eggs deposited in ovitraps' slides using image processing techniques, Congresso Brasileiro de Engenharia Biomédica (CBEB), pp. 635-638. Disponível em https://tinyurl.com/yaf3qqgt.

Elpídio, F. G. G., Costa, L. F. R., Andrade, M. M., Costa, E. A., Brasil, L. M. and Rodrigues, M. A. B. (2011). Contagem automática de ovos de Aedes aegypti depositadas em ovitrampas através de algoritmo de processamento digital de imagens e rede neural artificial, 2011 Pan American $\mathrm{He}^{-}$ alth Care Exchanges, pp. 138-139. Disponível em http://www.proceedings.com/11779.html.

Feitosa, L. d. N. (2015). Sistema de contagem automática de ovos do Aedes aegypti a partir de processamento de imagens das palhetas de ovitrampas, Graduação em análise e desenvolvimento de sistemas, Instituto Federal de Educação, Ciência e Tecnologia do Rio Grande do Norte, Pau dos Ferros, Brasil. Disponível em https://tinyurl.com/y4yu3whp.

Gaburro, J., Duchemin, J., Paradkar, P. N., Nahavandi, S. and Bhatti, A. (2016). Assessment of ICount software, a precise and fast egg counting tool for the mosquito vector Aedes aegypti, Parasites \& Vectors 9(1): 590598. https://doi.org/10.1186/s13071-016-1870-1.

Garcia, P. S. C., Martins, R., Lins Machado Coelho, G. L. and Cámara-Chávez, G. (2019). Acquisition of digital images and identification of aedes aegypti mosquito eggs using classification and deep learning, 2019 32nd SIBGRAPI Conference on Graphics, Patterns and Images (SIBGRAPI), pp. 47-53. https://doi.org/10.1109/SIBGRAPI.2019.00015.

Huang, J., Rathod, V., Sun, C., Zhu, M., Korattikara, A., Fathi, A., Fischer, I., Wojna, Z., Song, Y., Guadarrama, S. and Murphy, K. (2017). Speed/accuracy trade-offs for modern convolutional object detectors. URL: Disponível em https://arxiv.org/abs/1611.10012

Huang, L. and Wang, M. J. (1995). Image thresholding by minimizing the measures of fuzziness, Pattern Recognition 28(1): 41 - 51. https://doi.org/10.1016/00313203(94)E0043-K.
Kumar, V., Steinbach, M. and Tan, P.-N. (eds) (2009). Introdução ao Data Mining - Mineiração de Dados, 1 edn, Ciência Moderna, Rio de Janeiro, Brasil.

Mains, J. W., Mercer, D. R. and Dobson, S. L. (2008). Digital image analysis to estimate numbers of Aedes eggs oviposited in containers, Journal of the American Mosquito Control Association 24(4): 496-501. https://doi.org/10.2987/5740.1.

Mello, C. A. B., dos Santos, W. P., Rodrigues, M. A. B., Candeias, A. L. B. and Gusmao, C. M. G. (2008). Image segmentation of ovitraps for automatic counting of Aedes aegypti eggs, 2008 3oth Annual International Conference of the IEEE Engineering in Medicine and Biology Society, pp. 3103-3106. https://doi.org/10.1109/IEMBS.2008.4649860.

Mello, C. A. B., dos Santos, W. P., Rodrigues, M. A. B., Candeias, A. L. B., Gusmao, C. M. G. and Portela, N. M. (2009). Automatic counting of Aedes aegypti eggs in images of ovitraps, in G. R. Naik (ed.), Recent Advances in Biomedical Engineering, IntechOpen, Rijeka, chapter 11, pp. 211-222. https://doi.org/10.5772/7481.

Mollahosseini, A., Rossignol, M., Pennetier, C., Cohuet, A., Anjos, A., Chandre, F. and Shahbazkia, H. (2012). A user-friendly software to easily count anopheles egg batches, Parasites \& vectors 5: 122. https://doi.org/10.1186/1756-3305-5-122.

Morais, H. S., Santos, O. S., Rocha, M. A., Almeida, T. C. S., Brasil, L. M., Amvame-Nze, G. D., Miosso, C. J., Costa, M. V. C. and Pizo, G. A. (2015). Monitoring information system of Aedes aegypti reproduction, in D. A. Jaffray (ed.), World Congress on Medical Physics and Biomedical Engineering, June 7-12, 2015, Toronto, Canada, Springer International Publishing, Cham, pp. 1423-1426. https://doi.org/10.1007/9783-319-19387-8_347.

Morais, H. S., Santos, O. S., Rocha, M. A., Pizo, G. A. I., Brasil, L. M., Amvame-Nze, G. D. and et al (2014). Acquisition system for microscopic images for counting of eggs on ovitraps palettes, Pan American $\mathrm{He}$ alth Care Exchanges (PAHCE 2014) Conference, 7-12 April 
2014, Brasília, Brasil, Institute of Electrical and Electronics Engineers (IEEE), pp. 76-79. Disponível em http://www.proceedings.com/22680.html.

Mukherji, S. and Kaushik, S. (2015). Dengue: A runaway epidemic and a bewildered public health worker, Medical Journal Armed Forces India 71(1): 3 - 4. https://doi.org/10.1016/j.mjafi.2014.12.002.

Otsu, L. (1979). A threshold selection method from gray level histogram, IEEE Transactions Systems. Man. and Cybernetics 9: 62 - 67. https://doi.org/10.1109/TSMC.1979.4310076.

Paiva, P., Queiroz, F., Nunes, A., Josilaine, M. and Silva, M. (2016). Contagem automática de ovos do carrapato rhipicephalus (boophilus) microplus em imagens microscópicas, Conference on Graphics, Images and Patterns . Disponível em https://tinyurl.com/y95wfvbm.

Portela, N. M. (2009). Contagem automática de ovos de Aedes aegypti em imagens de ovitrampas, Mestrado em engenharia da computação, Escola Politécnica de Pernambuco da Universidade de Pernambuco, Recife, Brasil. Disponível em http://hdl.handle.net/10438/16722.

Portela, N. M., Mello, C. A. B., dos Santos, W. P., Candeias, A. L. B., Gusmão, C. M. G., Machado, S. C. S. and Rodrigues, M. A. B. (2009). A new algorithm for segmenting and counting Aedes aegypti eggs in ovitraps, 2009 Annual International Conference of the IEEE Engineering in Medicine and Biology Society, pp. 67146717. https://doi.org/10.1109/IEMBS.2009.5333759.

Rizzi, C. B., Brun, A. L., Galante, G. and Rizzi, R. L. (2016). Sigdengue: Um sistema de informação para o acompanhamento e gestão de ações sobre dengue com enfoque às atividades de notificação, raio e bloqueio, iSys - Revista Brasileira de Sistemas de Informação 9(1): 101-117. Disponível em https://tinyurl.com/yahnxcwv.

Rizzi et al., C. B. (2016). Preliminary studies using georeferenced ovitraps for to aedes aegypti's monitoring, V Modeling Symposium on Dengue. Disponível em http://www.inf.unioeste.br/ claudia/ANAIS2016.pdf.

Rocha, C. D. F., Bizerra, A. M. C., Coutinho, D. A. M., da Silva, L. F. V. and de Deus, M. S. (2019). Contagem automática de ovos do Aedes aegypti em palhetas de ovitrampas: um sistema para aquisição e processamento de imagens, Encontro Internacional de Jovens Investigadores (JOIN), pp. 67-74. https://doi.org/10.22533/at.ed.8721931017.

Santana Jr, C. J., Firmo, A. C. A., Oliveira, R. F. A. P., Lins, P. J. B., Lima, G. A. and Lima, R. A. (2019). A solution for counting aedes aegypti and aedes albopictus eggs in paddles from ovitraps using deep learning, IEEE Latin America Transactions 17(12): 19871994. https://doi.org/10.1109/TLA.2019.9011543.

Santos, W. P., Mello, C. A. B., Mesquita, R. G., Rodrigues, M. A. B., Candeias, A. L. B. and Gusmão, C.
M. G. (2008). Um algoritmo para contagem automática de ovos do mosquito Aedes aegypti em ovitrampas para controle da dengue, XXI Congresso Brasileiro de Engenharia Biomédica, pp. 1507-1510. Disponível em https://tinyurl.com/y88984bd.

Sayão, L. F. and Sales, L. F. (2015). Guia de Gestão de Dados de Pesquisa para Bibliotecários e Pesquisadores, CNEN/IEN, Rio de Janeiro, Brasil. Disponível em https://tinyurl.com/ydgyuj4a.

Schneider, C., Rasband, W. and Eliceiri, K. (2012). Nih image to imagej: 25 years of image analysis, Nature Methods 9. https://doi.org/10.1038/nmeth.2089.

Silva, C. E. and Limongi, J. E. (2018). Avaliação comparativa da eficiência de armadilhas para a captura e coleta de aedes aegypti em condições de campo, Cadernos Saúde Coletiva 26: 241 - 248. https://doi.org/10.1590/1414-462X201800030045.

Silva, M. G. N. M., Rodrigues, M. A. B. and Araujo, R. E. (2010). Um novo método de segmentação e contagem de ovos do Aedes aegypti em ovitrampas, Anais do XXII Congresso Brasileiro de Engenharia Biomédica (CBEB), pp. 861-865. Disponível em http://www.sbeb.org.br/site/wpcontent/uploads/XXIICBEB2010Vol2.pdf.

Silva, M. G. N. M., Rodrigues, M. A. B. and Araujo, R. E. (2011). Aedes aegypti egg counting system, 2011 Annual International Conference of the IEEE Engineering in Medicine and Biology Society, pp. 6810-6812. https://doi.org/10.1109/IEMBS.2011.6091679.

Silva, M. G. N. M., Rodrigues, M. A. B. and de Araujo, R. E. (2012). Sistema de aquisição e processamento de imagens de ovitrampas para o combate a dengue, Revista Brasileira de Engenharia Biomédica 28: 364 374. https://doi.org/10.4322/rbeb.2012.043.

Tiba, A. K. O., Araujo, A. F. R., Bassani, H. F. and Ren, T. I. (2011). Sistema autônomo de reconhecimento e contagem de ovos de Aedes aegypti, in G. d. A. Barreto and J. A. F. Costa (eds), Anais do 10 Congresso Brasileiro de Inteligência Computacional, SBIC, Fortaleza, CE, pp. 1-8. https://doi.org/10.21528/CBIC2011-27.4.

Waithe, D., Rennert, P., Brostow, G. and Piper, M. (2015). Quantifly: Robust trainable software for automated drosophila egg counting, PloS one 10: e0127659. https://doi.org/10.1371/journal.pone.0127659.

Wan Yussof, W. N. J. H., Man, M., Hitam, M. S., Hamid, A. A. K. A., Awalludin, E. A. and Bakar, W. A. W. A. (2018). Wavelet-based auto-counting tool of Aedes eggs, Proceedings of the 2018 International Conference on Sensors, Signal and Image Processing, SSIP 2018, ACM, New York, NY, USA, pp. 56-59. https://doi.org/10.1145/3290589.3290594. 